\title{
Impact of COVID-19 pandemic on Functional Urology Practice: A nation-wide survey from Turkey
}

\author{
Ahmet Tahra ${ }^{1}$, Murat Dinçer ${ }^{2}$, and Rahmi Onur ${ }^{3}$ \\ ${ }^{1}$ Istanbul Medeniyet University Faculty of Medicine \\ ${ }^{2}$ Health of Science University, Bağcllar Training and Research Hospital \\ ${ }^{3}$ Marmara University School of Medicine
}

May 10, 2021

\begin{abstract}
Objective The Coronavirus pandemic has affected urological practice worldwide. In this study, we aimed to evaluate functional urology practice including outpatient clinic visits, routine examinations, diagnostic procedures and surgical interventions with an online survey. Method We conducted an online survey to evaluate Turkish urologists' functional urology practices before and during the pandemic. In this survey, we asked questions about the respondents' place of work, being part of a dedicated pandemic center, involvement with the pandemic and an interest in functional urology. We also examined outpatient clinics, routine examinations, diagnostic methods, and surgical practice before and during the pandemic. Results A total of 152 urologists completed the survey. The majority of the participants, (79.6\%) were in tertiary centers. Nearly one-third of respondents $(32.2 \%)$ stated that more than $50 \%$ of their routine practice is related to functional urology. In brief, $80.9 \%$ of the participants declared a decrease in the number of outpatient visits for functional urology. 68.4\% of the participants declared a decrease in uroflowmetry practice, and $81.3 \%$ of had a decrease in urodynamic studies performed. According to respondents, $92.1 \%$ stated a decrease in botulinum injections for the bladder, and $93.4 \%$ of the participants declared a decrease in anti-incontinence surgery. Eighty-five percent of the participants declared a decrease in prolapse surgery. One-hundred and twenty-eight participants $(84.2 \%)$ declared a decrease in surgery for benign prostate hyperplasia (BPH). Only $28.9 \%$ of the participants responded that they diagnosed their neuro-urology patients as they did prior to the pandemic. Conclusions The daily practice of urology changed, and functional urology was one of the most affected field. The large backlog of functional urology patients is challenging and although conditions, diagnostic tools and surgeries were classed as "benign", we will have to face the effects of patients' Quality of life in the near future.
\end{abstract}

\section{Impact of COVID-19 pandemic on Functional Urology Practice: A nation-wide survey from Turkey \\ Objective}

The Coronavirus pandemic has affected urological practice worldwide. In this study, we aimed to evaluate functional urology practice including outpatient clinic visits, routine examinations, diagnostic procedures and surgical interventions with an online survey.

\section{Method}

We conducted an online survey to evaluate Turkish urologists' functional urology practices before and during the pandemic. In this survey, we asked questions about the respondents' place of work, being part of a dedicated pandemic center, involvement with the pandemic and an interest in functional urology. We also examined outpatient clinics, routine examinations, diagnostic methods, and surgical practice before and during the pandemic. 


\section{Results}

A total of 152 urologists completed the survey. The majority of the participants, (79.6\%) were in tertiary centers. Nearly one-third of respondents $(32.2 \%)$ stated that more than $50 \%$ of their routine practice is related to functional urology. In brief, $80.9 \%$ of the participants declared a decrease in the number of outpatient visits for functional urology. $68.4 \%$ of the participants declared a decrease in uroflowmetry practice, and $81.3 \%$ of had a decrease in urodynamic studies performed. According to respondents, $92.1 \%$ stated a decrease in botulinum injections for the bladder, and $93.4 \%$ of the participants declared a decrease in anti-incontinence surgery. Eighty-five percent of the participants declared a decrease in prolapse surgery. One-hundred and twenty-eight participants (84.2\%) declared a decrease in surgery for benign prostate hyperplasia (BPH). Only $28.9 \%$ of the participants responded that they diagnosed their neuro-urology patients as they did prior to the pandemic.

\section{Conclusions}

The daily practice of urology changed, and functional urology was one of the most affected field. The large backlog of functional urology patients is challenging and although conditions, diagnostic tools and surgeries were classed as "benign", we will have to face the effects of patients' Quality of life in the near future.

Keywords: Coronavirus, COVID-19, Functional Urology, Neurourology

\section{What's known}

Pandemic had largely affected the daily urological practice as well as other specialties.

Priorities were given to the patients with Coronavirus as expected thus resulted in a negative impact on urological patients.

\section{What's new}

We showed that most of the participants in several clinics declared a severe decrease in the functional urology practice including outpatient's clinical visit, diagnostic tools and surgical interventions.

Functional urology seemed to be one of the most affected fields of urology in this pandemic due to national and international recommendations.

\section{Introduction}

A novel coronavirus called SARS-CoV-2 is still challenging for healthcare professionals across the world. Although vaccinations are spreading widely, to date nearly 140 million people have been infected and 3 million people have died from the disease. ${ }^{1}$ After the World Health Organization (WHO) declared COVID-19 a pandemic, healthcare providers were faced with management difficulties.

To reduce the pressure on the healthcare system, national and international lockdowns were used and similar restrictions were carried for outpatient clinics and elective surgeries. Some urological associations released recommendations and others published data for healthcare professionals in the field of urology. ${ }^{2-5}$ There was a decrease in outpatient and inpatient clinics and surgery. ${ }^{6}$ The pandemic affected the management of all cases including oncological and emergency patients, however elective outpatient clinics and surgeries were affected the most and they were delayed for an unspecified period of time. The surgical practice of functional urology including benign prostate hyperplasia, all types of incontinence surgery, and genitourinary prolapse were the initial cases that have been postponed. Another limitation for functional urology was reducing or stopping all urodynamic studies. ${ }^{7}$

In this study, we aimed to evaluate functional urology practices including outpatient clinic visits, routine examinations, diagnostic procedures and surgical interventions by using an online survey among Turkish urologists. We also aimed to examine the effect of functional urological practices becoming dedicated pandemic centers, an interest in functional urology and the respondents' places of work

\section{Materials and methods}


After the Ministry of Health and Ethical Board's review (27.1.2021/no. 2021-0083), we conducted an online survey to evaluate Turkish urologists' functional urology practices before and during the pandemic. We sent the online survey (by Google Forms@) via direct message and used the Turkish Urological Association's mailing list of urology experts; it was sent between February and March 2021, (one month period). 152 experts in the field of urology responded to the 30-question survey which analyzed the respondents' fields of work, whether they were working in a dedicated pandemic center, took part in the care of COVID19 patients, and their interest in functional urology. We also questioned outpatient clinics about practices before and during the pandemic including the numbers of functional urology patients, routine examinations (including vaginal examinations), diagnostic methods (uroflowmetry and urodynamics), incontinence surgery (botulinum toxin injections for the bladder, anti-incontinence surgery), prolapse surgery, and fistula repair. Two other questions were answered by the respondents relating to treatment options for BPH patients and the management of neuro-urology patients during the pandemic.

All statistical analysis was carried out by the SPSS program (IBM Corp. released 2013. IBM SPSS Statistics for Windows, Version 22.0. Armonk, NY: IBM Corp.). Multiple-choice questions in the survey were illustrated with bar charts. All categorical variables were compared with Pearson's chi-squared test, and Fisher's exact test was used in a small number of samples. Post hoc analysis was done with the Bonferroni method to define which variables had statistical significance. For all of the analyses, a p-value under 0.05 was considered to be significant.

\section{Results}

A total of 152 urologists completed the survey. $79.6 \%$ of the participants were in tertiary centers $-45.4 \%$ in education and research hospitals, $34.2 \%$ in university hospitals - and only $7.9 \%$ of the participants were from private clinics. According to respondents, $73.7 \%$ of hospitals were dedicated pandemic centers and $70.4 \%$ of the participants took part in the care of COVID-19 patients. All participants had some functional urology practice and nearly one-third of respondents $(32.2 \%)$ stated that more than $50 \%$ of their routine practice is related to functional urology. (Table 1).

During pandemics, $80.9 \%$ of the participants declared a decrease in the number of outpatient visits for functional urology. In a subgroup analysis, the center of being or converting to a pandemic dedicated center were significant factors for the decreased number of patients $(\mathrm{p}=0.001)$ (Table 2-4).

Regarding the stress test for urinary incontinence diagnosis during urogynecological examination, only $2 / 3^{\text {rd }}$ of participants continued to perform stress test and $83.3 \%$ of the participants were using personal protective equipment (PPE) during the cough test. As an important diagnostic tool, uroflowmetry continued to be use but $68.4 \%$ of the participants stated a decrease. There were no significant difference between centers and being a pandemic dedicated center with regard to ratio of decrease in uroflowmetry tests, but interest in functional urology was found a significant factor for the decrease in uroflowmetry $(p=0.001)$ (Table 2-4). One-hundred and seven participants $(70.4 \%)$ responded as they had a urodynamic unit in their centers, however $81.3 \%$ of respondents had a decrease in urodynamic studies performed. In a subgroup analysis, a significant correlation was found between the decrease in the number of urodynamic studies and the centers that participated, $(\mathrm{p}=0.001)$ but being a dedicated pandemic center or having an interest in functional urology were not significant factors for the decrease in urodynamic studies(Table 2-4).

All participants declared that they were capable of performing anti-incontinence surgery, botulinum toxin injections for the bladder, performing prolapse surgery and surgery for benign prostate hyperplasia (BPH) prior to pandemics. According to the respondents, $92.1 \%$ stated a decrease in botulinum injections for the bladder. The participant's center was found to be a significant factor for the decrease in botulinum toxin injections (Table 2-4).

Approximately $94 \%$ of the participants declared a decrease in anti-incontinence surgery. The participant's center was found to be the sole significant factor for the decrease $(\mathrm{p}=0.001)$ (Table 2). Participants' treatment options for the patients who required anti-incontinence surgery are shown in Figure 1. Eighty five percent of the participants stated a decrease in prolapse surgery during pandemics. There was no significant factor 
for the decrease for prolapse surgery (Table 2-4). Majority of the participants stated that they preferred follow-up, medical treatment or pessaries for the patients who required prolapse surgery (Figure 2). Of the participants $93.5 \%$ who perform fistula repair surgery declared a decrease and there was no significant factor for the decrease for fistula repair (Table 2-4).

One-hundred and twenty-eight participants, $(84.2 \%)$, declared a decrease in surgery for BPH. There was no significant factor for the decrease in surgery of BPH. 143 participants, (94.1\%) declared that they preferred medical treatment, intermittent catheter/ suprapubic tube and surgery in local settings for patients who required surgery for BPH (Figure 3). Participants' approaches to treatments for their patients with new diagnosed high residual urine during COVID-19 is shown in Figure 4.

Participants' choice for neuro-urology patients during the pandemic were: "evaluate after pandemic" (38.2\%), "as usual as before pandemic" (28.9\%), "tele-medicine to evaluate their situation" (17.8\%) and "urodynamic studies but not invasive procedures" (15.1\%).

\section{Discussion}

The novel virus named SARS-CoV-2 spreads rapidly and it is still a major threat across the world. Vaccinations and some clinical drugs trials for COVID-19 are promising but devastation continues. During the first wave in Turkey, (mid-March 2020), some restrictions were set by the government: national lockdowns, delays for all types of elective surgeries, restrictions for outpatient clinics and reductions in the number of hospitalization. Additionally, healthcare professionals were repositioned during the pandemic and nearly all the tertiary centers and government hospitals became dedicated pandemic centers in Turkey. Major associations of urology and ministry of health regularly published recommendations for urological practice during COVID-19 $9^{2,3,6,7}$. These regulations and restrictions resulted in a major decrease in routine urological procedures.

In this online survey, we evaluated the daily practice of functional urology during COVID pandemics. We showed that $80.9 \%$ of the participants declared a decrease in the number of outpatient visits, and nearly $85 \%$ of the participants reported a decrease in surgical interventions for functional urology. Our results are consistent with a survey from Brazil where the authors found that $80 \%$ of the participants reported a reduction of [?]50\% in elective surgery. ${ }^{8}$ Similarly, Paffenholz et al. investigated the impact of the pandemic on German urologists, and they showed that $77.8 \%$ of the participants stated their routine practice of surgical interventions changed and they had not performed any surgery except for uro-oncology. ${ }^{9}$ In another online survey on Polish urologists, the pandemic had also negatively affected their routine practice. ${ }^{10}$

All parts of urology practice were affected during the pandemic. Studies that evaluated the effect of pandemic showed a $40 \%-82 \%$ decrease in the number of outpatient clinics. ${ }^{11,12}$ The reasons for the decrease can be attributed to guidelines' and published data recommendations, measures taken by the government, and restrictions made in hospitals to maintain the care of COVID patients. Similarly, healthcare professionals concerned about themselves and their surgical teams in relation to COVID-19 infections, and the absence of useful information regarding the transmission of the virus in surgical procedures, might have encouraged the surgeons to delay surgery, especially for elective cases. ${ }^{13}$ Becoming a part of pandemic clinics may also be another reason for the decrease in urological practice. Regional and interstate differences in the same country are also factors that affected the decrease of urological patients, too. ${ }^{8,11}$ Turkey is one of the most affected countries in the world from COVID-19 with a high number of coronavirus cases. In the challenging times of the pandemic, the Ministry of Health organized restrictions across the whole country to high-risk groups, restricted elective surgeries and the number of inpatients and outpatients. A single-center study from our country compared practice eight weeks before and during the pandemic showed a decrease in the number of patients examined, and the number of non-surgical and surgical interventions. ${ }^{14} \mathrm{In}$ another trial that assessed the effect of the pandemic on urological practice and the anxiety levels of patients on the waiting list for surgery, the authors found a significant decrease in the number of patients for inpatient and outpatient clinics and surgical interventions. ${ }^{15}$ Similarly in a large cohort from Turkey, Bozkurt et al evaluated the impact of the pandemic on urology practice in 51 centers from all geographical parts of the 
country. The authors found a decrease in the number of inpatients, outpatients and surgical interventions especially in tertiary centers at the beginning of the pandemic. They also evaluated the workload comparing it with the same period before and during the pandemic and found a huge decrease in all fields of urology. ${ }^{16}$

Functional urology seems to be one of the most affected subspeciality of urological practice. Due to guidelines, published data and measures taken by the government and/or hospital, it is very challenging to have regular clinical practice during times of the pandemic. In most of the centers all kinds of interventions were delayed except for the second stage of sacral neuromodulation and infected patients with artificial urethral sphincter. ${ }^{2-5,7}$ In one study, Cakici et al investigated the impact of the pandemic on urological practice in the first three months of pandemics. They showed a cumulative decrease in admissions, but the majority of the decreases were seen in incontinence, pediatric urology and andrology subspecialties. They also found an approximately $75 \%$ decrease in surgical interventions and a significant decrease in the number of transurethral resections of the prostate, transvesical prostatectomy, and transobturator tape surgeries. ${ }^{17}$ Teoh et al conducted a global survey on the impact of COVID-19 in urology practice and found a delay of over eight weeks for nearly $30 \%$ of outpatient clinics, ) outpatient urological activities and surgical procedures. The most affected delays were in benign conditions of urology practice and particularly BPH surgery (93\%); female urinary incontinence $(85 \%)$ had the highest rates of delays. ${ }^{18}$ An online survey from Brazil showed that $68.7 \%$ of the participants did not perform non-essential surgery and this rate went up to $75.5 \%$ for participants in the high incidence states. ${ }^{8}$ The Italian Society of Urodynamics specifically evaluated the impact of the pandemic on pelvic floor dysfunction patients and showed that the overall cancellation rate was $78.4 \%$ for outpatient clinics and $82.7 \%$ for surgery. They also showed that mean cancellation rates for intravesical botulinum toxin injections was $82.2 \%$. It was $85.6 \%$ for stress urinary incontinence, $85.1 \%$, for prolapse surgery, $77.9 \%$ for benign prostate hyperplasia, $80.6 \%$ for perineal fistulas. ${ }^{19}$

Urodynamic investigation is an important diagnostic tool in functional urology practice. After the first wave of the pandemic, published data suggested delaying nearly all urodynamic studies. ${ }^{7}$ Following these recommendations, Hashim et al presented adaptation guidelines for urodynamic studies for the pandemic if they were deemed crucial for patients. ${ }^{20}$ In our study, approximately $80 \%$ of the participants declared a decrease in urodynamic studies and $68.4 \%$ of them declared a decrease in uroflowmetry. Similarly, in a global survey, Teoh et al showed an $87 \%$ reduction in urodynamic studies and an $83 \%$ reduction in uroflowmetry testing. ${ }^{18}$ In another survey, it was shown that overall cancellation rates for uroflowmetry was $79.1 \%$ and $81.2 \%$ for urodynamic studies. ${ }^{19}$ The decrease of urodynamic studies may be explained by the uncertainty of the limitations, especially during the first wave of the pandemic. Protective equipment supplies, guidelines recommendations and the reduction in clinical visits may be other reasons for the decrease.

During the pandemic, telemedicine in clinical practice has been accepted as an alternative for consults and strategy development for diagnosis and disease management. ${ }^{9,11,19,21}$ However, in our survey, we showed only $17.8 \%$ of the participants decided to use telemedicine in neuro-urology patients. A study by Dubin et al. revelaed increased use of telemedicine by urologists, with the majority of the urologists declaring they wanted to continue using it in their routine practice. ${ }^{22}$ Although, our results showed a lower ratio of preference of telemedicine in Turkey, it seems a gradual increase day by day. This fact was supported by the survey that evaluated patients' perspective for telemedicine during pandemic and showed that majority of the patients wished for telemedicine $(84.7 \%)$ rather than clinical visits. ${ }^{23}$

We found that functional urology was less affected in private practice. Although, respondents from private practice constituted $7.9 \%$ of the cohort, $83.3 \%$ of the participants declared no decrease in the number of patients. There was a slight decrease in urodynamic studies and surgery for incontinence but these ratios were lower than the other government reimbursed hospitals. Similarly, a survey by Gravas et al. found that surgical interventions were less restricted in private practice compared with academic or public practice. ${ }^{11}$ In another study that compared the impact of the pandemic in private and public clinics, urological practice showed a similar reduction - except in surgery for BPH - in both centres. ${ }^{24}$

In the first wave of the pandemic, the cancellation of routine functional urological practice was inevitable. The backlog of patients, especially those who are waiting for surgical interventions seems to be a major 
problem. Many patients suffer from delays and the long-term implications are still unknown. In an online survey, Sacco et al also showed that $87 \%$ of the participants believed postponing services harmed patients' quality of life (QoL), and $48.2 \%$ of the respondents reported that there was a risk of potential health issues for the patients. They also showed based on projections, the estimated recovery for the backload of functional urological surgeries would take 28-64 months. In another study, it was shown that anxiety and depression scores were found to be higher for patients on surgery waiting lists. ${ }^{15}$. Postponing surgery for especially for benign conditions is widely accepted, but long-term outcomes including anxiety, depression and quality of life may be our challenge for the future. Delays in interventions during the pandemic may negatively affect clinical findings and affect overall outcomes, and this will be another concern.

The main strengths of this study were that nearly $80 \%$ of the participants were from tertiary centers and worked in dedicated pandemic centers reflecting the effects of pandemic on all urology practice. The majority of the respondents were interested in functional urology, which also can show the real-life change of functional urology during the pandemic. Although this study has several strengths there were some limitations. The rate of the respondents was lower than expected and a single-country trial could not reflect real-world data. The design and the questions were not validated. Timeline changes of the pandemic were not evaluated nor questioned in any detail. The number of participants from private practice was low and therefore could not reflect the real effect for private practice which may differ from country to country.

\section{Conclusions}

The COVID-19 pandemic put a strain on healthcare systems across the world. The daily practice of urology changed, and functional urology was one of the most affected subspeciality of urology. Various studies and urology associations have made recommendations for delaying diagnostic studies and treatments for nearly all patients for functional urology. In this study, most of the participants in several clinics declared significant decrease in functional urology practice including outpatient visits, diagnostic tools and surgery. The large backlog of functional urology patients seems to be challenging. Although such surgeries may be categorized as "surgeries for benign reasons" or "elective", health care system will eventually face the enormous patient load and the consequences of delaying all procedures and decreased quality of life in patients.

\section{ACKNOWLEDGEMENTS}

None declared.

\section{DISCLOSURE}

The authors have declared no conflicts of interest for this article

\section{References}

1. WHO. COVID-19 Dashboard. 2021;https://covid19.who.int/Accessed April 2021.

2. Ribal MJ, Cornford P, Briganti A, et al. European Association of Urology Guidelines Office Rapid Reaction Group: An Organisation-wide Collaborative Effort to Adapt the European Association of Urology Guidelines Recommendations to the Coronavirus Disease 2019 Era.Eur Urol. 2020;78(1):21-28.

3. Stensland KD, Morgan TM, Moinzadeh A, et al. Considerations in the Triage of Urologic Surgeries During the COVID-19 Pandemic. Eur Urol. 2020;77(6):663-666.

4. Lopez-Fando L, Bueno P, Carracedo D, et al. Management of Female and Functional Urology Patients During the COVID Pandemic. Eur Urol Focus. 2020;6(5):1049-1057.

5. Goldman HB, Haber GP. Recommendations for Tiered Stratification of Urological Surgery Urgency in the COVID-19 Era. J Urol.2020;204(1):11-13.

6. Puliatti S, Eissa A, Eissa R, et al. COVID-19 and urology: a comprehensive review of the literature. BJU Int.2020;125(6):E7-E14. 
7. Ficarra V, Novara G, Abrate A, et al. Urology practice during the COVID-19 pandemic. Minerva Urol Nefrol. 2020;72(3):369-375.

8. Gomes CM, Favorito LA, Henriques JVT, et al. Impact of COVID-19 on clinical practice, income, health and lifestyle behavior of Brazilian urologists. Int Braz J Urol. 2020;46(6):1042-1071.

9. Paffenholz P, Peine A, Fischer N, et al. Impact of the COVID-19 Pandemic on Urologists in Germany. Eur Urol Focus.2020;6(5):1111-1119.

10. Rajwa P, Przydacz M, Zapala P, et al. How has the COVID-19 pandemic impacted Polish urologists? Results from a national survey. Cent European J Urol. 2020;73(3):252-259.

11. Gravas S, Bolton D, Gomez R, et al. Impact of COVID-19 on Urology Practice: A Global Perspective and Snapshot Analysis. J Clin Med.2020;9(6).

12. Diokno AC, Devries JM. The impact of COVID-19 on urologic practice, medical education, and training. Int Urol Nephrol.2020;52(7):1195-1198.

13. Kunz Y, Horninger W, Pinggera GM. Are urologists in trouble with SARS-CoV-2? Reflections and recommendations for specific interventions. BJU Int. 2020;126(6):670-678.

14. Soytas M, Boz MY, Guzelburc V, et al. Comparison of before and after COVID-19 urology practices of a pandemic hospital. Turk J Urol.2020;46(6):474-480.

15. Micoogullari U, Kisa E, Yucel C, et al. The effect of the first wave of COVID-19 pandemic on urology practice and anxiety scores of patients awaiting surgery. Int J Clin Pract. 2021:e14201.

16. Bozkurt O, Sen V, Irer B, et al. Nation-wide analysis of the impact of Covid-19 pandemic on daily urology practice in Turkey. Int J Clin Pract. 2021;75(4):e13735.

17. Cakici MC, TemIz MZ, IplIk CA, et al. The clinical impact of the COVID-19 pandemic on daily urological practice: First 3 month multicenter results from Istanbul. Turk J Med Sci. 2021.

18. Teoh JY, Ong WLK, Gonzalez-Padilla D, et al. A Global Survey on the Impact of COVID-19 on Urological Services. Eur Urol.2020;78(2):265-275.

19. Sacco E, Gandi C, Li Marzi V, et al. Extensive impact of COVID-19 pandemic on pelvic floor dysfunctions care: A nationwide interdisciplinary survey. Neurourol Urodyn. 2021;40(2):695-704.

20. Hashim H, Thomas L, Gammie A, Farullo G, Finazzi-Agro E. Good urodynamic practice adaptations during the COVID-19 pandemic.Neurourol Urodyn. 2020;39(6):1897-1901.

21. Novara G, Checcucci E, Crestani A, et al. Telehealth in Urology: A Systematic Review of the Literature. How Much Can Telemedicine Be Useful During and After the COVID-19 Pandemic? Eur Urol.2020;78(6):786-811.

22. Dubin JM, Wyant WA, Balaji NC, et al. Telemedicine Usage Among Urologists During the COVID-19 Pandemic: Cross-Sectional Study. J Med Internet Res. 2020;22(11):e21875.

23. Boehm K, Ziewers S, Brandt MP, et al. Telemedicine Online Visits in Urology During the COVID-19 Pandemic-Potential, Risk Factors, and Patients' Perspective. Eur Urol. 2020;78(1):16-20.

24. Zouari S, Saadi A, Chakroun M, et al. Urological activity at the time of COVID-19 pandemic: is there any difference between public and private field? Pan Afr Med J. 2020;37:389.

Table 1-Demographics of participants $(\mathrm{N}=152)$

Characteristics

Centers of Participants Education and Research Hospital University Hospital Government Hospital Private Clinic Pandemic dedicated Center Yes No
$\mathrm{N}(\%)$

$69(45.4$

$112(73$. 


\begin{tabular}{ll}
\hline Characteristics & $\mathrm{N}(\%)$ \\
\hline Took part in the care of COVID-19 patients Yes No & $107(70$. \\
Interest in Functional Urology $<25 \% 25-50 \%>50 \%$ & $56(36$. \\
\hline
\end{tabular}

Table 2- Decrease in functional urology practice according to centers of participants

\begin{tabular}{lll}
\hline & Education and Research Hospital $(\%)$ & University Hospital $(\%)$ \\
\hline Outpatient clinical visit & Outpatient clinical visit & Outpatient clinical v \\
Decrease & 88.4 & 80.7 \\
Same or increase & 11.6 & 19.3 \\
Uroflowmetry & Uroflowmetry & Uroflowmetry \\
Decrease & 66.7 & 71.2 \\
Same or increase & 33.3 & 28.8 \\
Urodynamic studies & Urodynamic studies & Urodynamic studies \\
Decrease & 82.6 & 87.7 \\
Same or decrease & 17.4 & 12.3 \\
Botulinum toxin injections & Botulinum toxin injections & Botulinum toxin inje \\
Decrease & 97.1 & 88.5 \\
Same or increase & 2.9 & 11.5 \\
Anti-incontinence surgery & Anti-incontinence surgery & Anti-incontinence su \\
Decrease & 98.6 & 96.2 \\
Same or increase & 1.4 & 3.8 \\
Surgery for Prolapsus & Surgery for Prolapsus & Surgery for Prolapsu \\
Decrease & 89.9 & 76.9 \\
Same or increase & 10.1 & 23.1 \\
Fistula Repair & Fistula Repair & Fistula Repair \\
Decrease & 95.5 & 92.5 \\
Same or increase & 4.5 & 7.5 \\
Surgery for Benign Prostate Hyperplasia & Surgery for Benign Prostate Hyperplasia & Surgery for Benign \\
Decrease & 84.1 & 92.5 \\
Same or increase & 15.9 & 7.5 \\
\hline
\end{tabular}

+ Considered with post-hoc analysis

Table 3- Decrease in functional urology practice according to being pandemic dedicated center

\begin{tabular}{lll}
\hline & Being a pandemic dedicated center & Being a pandemic dedic \\
\hline & Yes $(\%)$ & No(\%) \\
Outpatient clinical visit & Outpatient clinical visit & Outpatient clinical v \\
Decrease & 87.5 & 62.5 \\
Same or increase & 12.5 & 37.5 \\
Uroflowmetry & Uroflowmetry & Uroflowmetry \\
Decrease & 68.8 & 67.5 \\
Same or increase & 31.2 & 32.5 \\
Urodynamic studies & Urodynamic studies & Urodynamic studies \\
Decrease & 80.8 & 82.8 \\
Same or decrease & 19.2 & 17.2 \\
Botulinum toxin injections & Botulinum toxin injections & Botulinum toxin inje \\
Decrease & 94.6 & 85
\end{tabular}




\begin{tabular}{lll}
\hline & Being a pandemic dedicated center & Being a pandemic dedic \\
\hline Same or increase & 5.4 & 15 \\
Anti-incontinence surgery & Anti-incontinence surgery & Anti-incontinence su \\
Decrease & 93.8 & 92.5 \\
Same or increase & 6.3 & 7.5 \\
Surgery for Prolapsus & Surgery for Prolapsus & Surgery for Prolapsu \\
Decrease & 86.6 & 80 \\
Same or increase & 13.4 & 20 \\
Fistula Repair & Fistula Repair & Fistula Repair \\
Decrease & 93 & 95.2 \\
Same or increase & 7 & 4.8 \\
Surgery for Benign Prostate Hyperplasia & Surgery for Benign Prostate Hyperplasia & Surgery for Benign \\
Decrease & 83.9 & 85 \\
Same or increase & 16.1 & 15 \\
\hline
\end{tabular}

+ Fisher-exact test

Table 4- Decrease in functional urology practice according to interest in functional urology

\begin{tabular}{|c|c|c|c|c|}
\hline & $\begin{array}{l}\text { Interest in } \\
\text { functional urology } \\
\text { practice (\%) (The } \\
\text { rate of functional } \\
\text { urology practice } \\
\text { in their routine } \\
\text { work) }\end{array}$ & $\begin{array}{l}\text { Interest in } \\
\text { functional urology } \\
\text { practice (\%) (The } \\
\text { rate of functional } \\
\text { urology practice } \\
\text { in their routine } \\
\text { work) }\end{array}$ & $\begin{array}{l}\text { Interest in } \\
\text { functional urology } \\
\text { practice }(\%) \text { (The } \\
\text { rate of functional } \\
\text { urology practice } \\
\text { in their routine } \\
\text { work) }\end{array}$ & \\
\hline & $\operatorname{Low}(\mathrm{n}=56)(<25 \%)$ & $\begin{array}{l}\text { Medium(n=47) } \\
(25-50 \%)\end{array}$ & $\operatorname{High}(\mathrm{n}=49)(>50 \%)$ & $\mathrm{p}$ value* \\
\hline $\begin{array}{l}\text { Outpatient } \\
\text { clinical visit }\end{array}$ & $\begin{array}{l}\text { Outpatient } \\
\text { clinical visit }\end{array}$ & $\begin{array}{l}\text { Outpatient } \\
\text { clinical visit }\end{array}$ & $\begin{array}{l}\text { Outpatient } \\
\text { clinical visit }\end{array}$ & $\begin{array}{l}\text { Outpatient } \\
\text { clinical visit }\end{array}$ \\
\hline Decrease & 82.1 & 87.2 & 73.5 & 0.22 \\
\hline Same or increase & 17.9 & 12.8 & 26.5 & \\
\hline Uroflowmetry & Uroflowmetry & Uroflowmetry & Uroflowmetry & Uroflowmetry \\
\hline Decrease & 55.4 & 66 & 85.7 & 0.03 \\
\hline Same or increase & 44.6 & 34 & 14.3 & \\
\hline $\begin{array}{l}\text { Urodynamic } \\
\text { studies }\end{array}$ & $\begin{array}{l}\text { Urodynamic } \\
\text { studies }\end{array}$ & $\begin{array}{l}\text { Urodynamic } \\
\text { studies }\end{array}$ & $\begin{array}{l}\text { Urodynamic } \\
\text { studies }\end{array}$ & $\begin{array}{l}\text { Urodynamic } \\
\text { studies }\end{array}$ \\
\hline Decrease & 76.3 & 75.9 & 90 & 0.22 \\
\hline Same or decrease & 23.7 & 24.1 & 10 & \\
\hline $\begin{array}{l}\text { Botulinum } \\
\text { toxin injections }\end{array}$ & $\begin{array}{l}\text { Botulinum } \\
\text { toxin injections }\end{array}$ & $\begin{array}{l}\text { Botulinum } \\
\text { toxin injections }\end{array}$ & $\begin{array}{l}\text { Botulinum } \\
\text { toxin injections }\end{array}$ & $\begin{array}{l}\text { Botulinum } \\
\text { toxin injections }\end{array}$ \\
\hline Decrease & 94.6 & 93.6 & 87.8 & $0.41+$ \\
\hline Same or increase & 5.4 & 6.4 & 12.3 & \\
\hline $\begin{array}{l}\text { Anti- } \\
\text { incontinence } \\
\text { surgery }\end{array}$ & $\begin{array}{l}\text { Anti- } \\
\text { incontinence } \\
\text { surgery }\end{array}$ & $\begin{array}{l}\text { Anti- } \\
\text { incontinence } \\
\text { surgery }\end{array}$ & $\begin{array}{l}\text { Anti- } \\
\text { incontinence } \\
\text { surgery }\end{array}$ & $\begin{array}{l}\text { Anti- } \\
\text { incontinence } \\
\text { surgery }\end{array}$ \\
\hline Decrease & 94.6 & 93.6 & 91.8 & $0.91+$ \\
\hline Same or increase & 5.4 & 6.4 & 8.2 & \\
\hline Surgery for & Surgery for & Surgery for & Surgery for & Surgery for \\
\hline Prolapsus & Prolapsus & Prolapsus & Prolapsus & Prolapsus \\
\hline
\end{tabular}




\begin{tabular}{lllll}
\hline & $\begin{array}{l}\text { Interest in } \\
\text { functional urology } \\
\text { practice (\%) (The } \\
\text { rate of functional } \\
\text { urology practice } \\
\text { in their routine } \\
\text { work) }\end{array}$ & $\begin{array}{l}\text { Interest in } \\
\text { functional urology } \\
\text { practice (\%) (The } \\
\text { rate of functional } \\
\text { urology practice } \\
\text { in their routine } \\
\text { work) }\end{array}$ & $\begin{array}{l}\text { Interest in } \\
\text { functional urology } \\
\text { practice (\%) (The } \\
\text { rate of functional } \\
\text { urology practice } \\
\text { in their routine } \\
\text { work) }\end{array}$ & \\
& 91.1 & 85.1 & 77.6 & 0.15 \\
Decrease & 8.9 & 14.9 & 22.4 & Fistula Repair \\
Same or increase & Fistula Repair & Fistula Repair & Fistula Repair & Fir.3 \\
Fistula Repair & 96.7 & 88.9 & 5.7 & $0.57+$ \\
Decrease & 3.3 & $\begin{array}{l}11.1 \\
\text { Surgery for }\end{array}$ & $\begin{array}{l}\text { Surgery for } \\
\text { Benign }\end{array}$ & Surgery for \\
Surgery for & Surgery for & Benign & Prostate & Prostate \\
Benign & Benign & Prostate & Hyperplasia & Hyperplasia \\
Prostate & Prostate & Hyperplasia & 85.7 & 0.88 \\
Hyperplasia & Hyperplasia & 85.1 & 14.3 & \\
Decrease & 82.1 & 14.9 & & \\
Same or increase & 17.9 & &
\end{tabular}

* Considered with post-hoc analysis

+ Fisher-exact test

\section{Figure Legends}

Figure 1- Participants' treatment options for the patients who required anti-incontinence surgery.

Figure 2- Participants' preferred option for the patients who required prolapse surgery.

Figure 3- Participants' approaches for their patients who required surgery for BPH.

Figure 4- Participants' approaches to treatments for their patients with new diagnosed high residual urine during COVID-19.

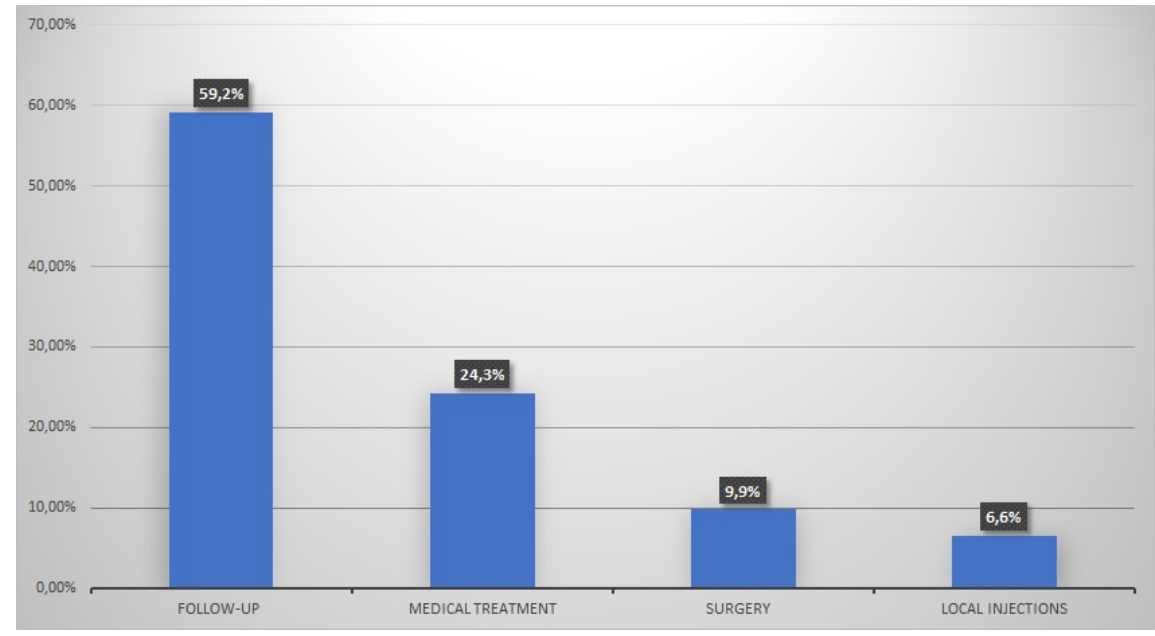



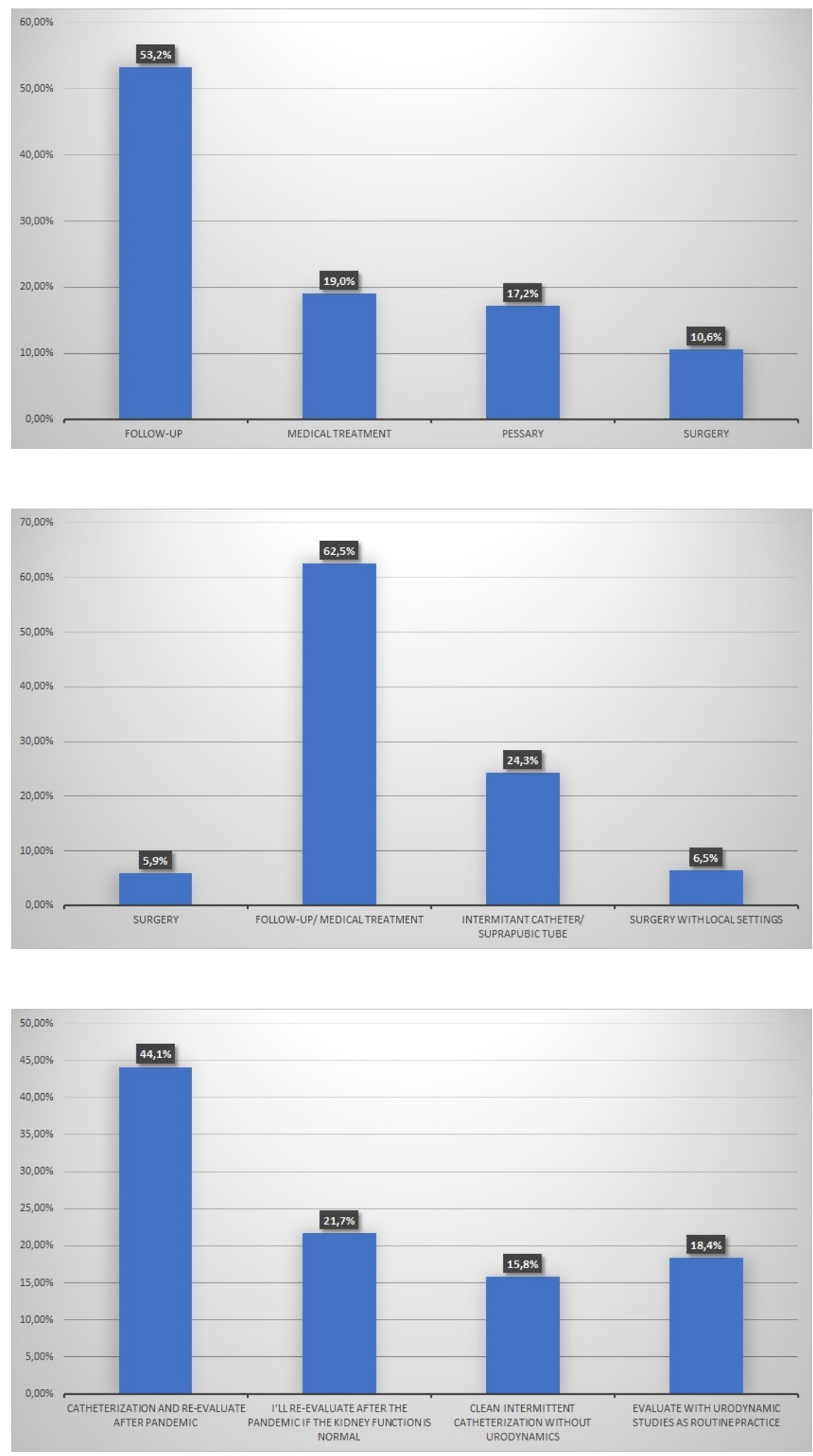